\title{
Community perceptions of barriers to stroke recovery and prevention in greater Kampala, Uganda: Implications for policy and practice
}

\author{
Carol Blixen*1, Jane Nakibuuka², Mark Kaddumukasa², Haddy Nalubwama ${ }^{3}$, Mathew Amollo³, Elly Katabira², Martha \\ Sajatovic ${ }^{1}$ \\ ${ }^{1}$ Neurological and Behavioral Outcomes Center, University Hospitals Cleveland Medical Center, Cleveland, USA \\ ${ }^{2}$ Department of Medicine, School of Medicine, Makerere University College of Health Sciences, Kampala, Uganda \\ ${ }^{3}$ School of Public Health, Makerere University College of Health Sciences, Kampala, Uganda
}

Received: March 29, 2017

DOI: $10.5430 /$ ijh.v3n2p 8
Accepted: May 22, 2017

Online Published: June 5, 2017

\begin{abstract}
Objective: Stroke risk and stroke burden are increasing in Sub Saharan Africa. Qualitative analysis was used to assess perceived barriers to stroke recovery and prevention in an urban/suburban Ugandan population in order to refine and implement a promising nurse and peer-led self-management intervention previously conducted in the United States.

Methods: In depth interviews and focus groups were conducted with 48 participants (stroke survivors, caretakers, and those at risk for stroke). All interviews and focus groups were audiotaped, transcribed verbatim, and analyzed using content analysis, with an emphasis on dominant themes.

Results: Three major domains of perceived barriers to stroke recovery and prevention emerged from the data: (1) Individual barriers (PTSD, stress, resistance to seeking care, medication non-adherence, unhealthy lifestyles, functional impairment, and a paucity of stroke knowledge); (2) Family/community barriers (lack of family and community support and caretaker burden); and (3) Provider and healthcare system barriers (lack of access and inadequate follow-up). Importantly, participants in this study identified a pressing need for increasing stroke awareness in the community as part of recovery and prevention efforts.

Conclusions: Stroke risk reduction efforts implemented at the patient, community, and healthcare system levels are needed. These efforts could, perhaps, be modeled along the lines of a previous very successful public health initiative to reduce HIV burden in Uganda.
\end{abstract}

Key Words: Stroke, Burden, Uganda, Barriers, Recovery, Prevention

\section{INTRODUCTION}

Stroke is a rapidly increasing burden in many low- and middle income countries and is associated with high fatality rates, high morbidity, years of suffering and disability for stroke survivors and families, as well as escalating costs. ${ }^{[1-3]}$
Worldwide in 2005, there were an estimated 16 million new strokes, and 62 million stroke survivors ${ }^{[4,5]}$ with future rates expected to increase. While stroke is a growing concern globally, Sub Saharan Africa is particularly hard-hit by the stroke burden due to rapid growth in population size, expanding

${ }^{*}$ Correspondence: Carol Blixen, PhD; Email: cxb28@case.edu; Address: Neurological and Behavioral Outcomes Center, University Hospitals Cleveland Medical Center, 11100 Euclid Avenue, Cleveland, OH 44106, USA. 
lifespan, patterns of industrialization, adoption of harmful western diets, and increasing prevalence of risk factors such as hypertension, obesity, and diabetes. ${ }^{[6,7]}$ Other broader environmental factors that may impact the rising increase in stroke burden are issues such as access to health care, accessibility and availability of healthy foods, and transportation. Stroke in Sub Saharan Africa accounts for 15\% of hospital admissions, and is a major contributor to mortality in both urban and rural areas. ${ }^{[8]}$

Interventions such as control of hypertension, hyperlipidemia and diabetes mellitus, and behavioral modifications such as smoking cessation, change in diet, weight loss, exercise and stress management can drastically reduce recurrent stroke risk, ${ }^{[5]}$ and improve health outcomes. ${ }^{[9]}$ However, awareness of stroke, its risk factors and symptoms is low in community studies conducted in Sub Saharan Africa. ${ }^{[10,11]}$ A recent cross-sectional study of 1,616 urban and rural participants on stroke risk factors in central Uganda, revealed only 402 (24.9\%) participants had heard about stroke; and nearly $75 \%$ did not know any stroke risk factors and warning signs, or recognize the brain as the affected organ. ${ }^{[12]}$

Given the disproportionate burden and tremendous humanitarian and financial impact related to stroke in Sub Saharan Africa, there is a critical need for healthcare approaches that will reduce stroke risk, and ultimately, the burden of stroke in this area. Chronic disease self-management programs can empower patients and improve health outcomes by emphasizing the central role of the individual in managing their health while collaborating with health care professionals and systems. ${ }^{[13]}$ Although a number of reports support selfmanagement training for stroke survivors, there is limited data specific to populations in Sub Saharan Africa. ${ }^{[14-17]}$ Approaches that target people with stroke or stroke risk factors, and address self-management could potentially reverse the often bleak prognosis for this high risk group. However, selfmanagement is challenging for individuals who are stroke survivors or at risk for stroke, and there are roadblocks that can impede progress and success. Additional information is needed on salient, and potentially modifiable, barriers to inform the development of acceptable and effective interventions.

To address this need, we conducted a qualitative analysis of barriers to stroke recovery and prevention in an urban Ugandan population. Qualitative inquiry is an appropriate framework for learning how patients conceptualize their experience of disease, and qualitative research techniques have become an integral component to developing health promotion interventions in special populations. This type of inquiry was instrumental in helping to refine and implement

Published by Sciedu Press a self-management training program called TEAM (TargetEd mAnageMent) for Uganda. TEAM has demonstrated promising outcomes with respect to reducing recurrent stroke risk among young African American male stroke survivors in the United States. ${ }^{[18-20]}$ This curriculum- guided program used Peer Dyads (African American men who had a stroke or TIA and their care partners) to provide support and model behaviors intended to improve post-stroke care. Further details of the program are described elsewhere. ${ }^{[20]}$

\section{Methods}

\subsection{Sample and setting}

Participants $(\mathrm{N}=48)$ were recruited from a sub-sample of 440 community subjects enrolled in a larger cross-sectional survey of stroke knowledge and attitudes in Mukono Municipality, an urban district in greater Kampala, Uganda. ${ }^{[21]}$ For qualitative research, this sample size is within the recommended number of 20-50 individuals. ${ }^{[22,23]}$ Inclusion criteria consisted of being age 18 years or older, cognitively intact, and able to provide informed consent. Exclusion criteria consisted of being unable to provide consent or having sickle-cell disease. In order to enhance the credibility and validity of the results, multiple types of informants, representing different segments of the population under study, were recruited as participants. ${ }^{[24]}$ These included stroke survivors, caregivers to stroke survivors, and individuals having two stroke risk factors (hypertension plus one other factor). In addition a sampling grid, designed to provide variability in gender and age, was used in the recruitment of these participants.

The study was approved by the institutional review boards (IRB) of both Makerere University College of Health Sciences' School of Medicine in Kampala, Uganda and University Hospitals in Cleveland, Ohio, United States. Additionally, all participants signed an informed consent form. In-depth interviews were then conducted with nine stroke survivors who had previously been hospitalized at Mulago hospital in Kampala, and eight caretakers of stroke survivors, who were not necessarily related to them. In addition, 4 separate focus groups, consisting of 31 community members were conducted with individuals who had one or more risk factors for stroke. All interviews were conducted at the respondents' homes, and focus groups were conducted at the local council chairperson's residence, by members of the research team.

The mean age of the nine stroke survivors was 63 years (SD = 15.0) with a range of 35 to 85 years, and the mean time since the stroke was 5 years (SD (3.85) with a range of 1-13 years. Seven $(78 \%)$ were married, and eight $(89 \%)$ were female. Four $(44 \%)$ had received a primary education, three (33\%) 
had a secondary education, one $(11 \%)$ had a tertiary education, and one $(11 \%)$ had received no formal education. The majority $(78 \%)$ were unemployed at the time of the interview. Of these unemployed stroke survivors, $33.3 \%$ had retired before the stroke, and $44 \%$ were currently unemployed due to a stroke.

The mean age of the eight caretakers was 47 years $(\mathrm{SD}=15.3)$ with a range of 24 to 68 years. Five $(63 \%)$ were married, and six $(75 \%)$ were female. Half $(50 \%)$ had received only a primary education, while one $(12 \%)$ received a secondary education, and three $(38 \%)$ had a tertiary education. Of the eight caretakers, six $(75 \%)$ were employed, one (12\%) was retired, and one $(12 \%)$ was unemployed. Two $(25 \%)$ of the caretakers were wives of stroke survivors, and $4(50 \%)$ were either a daughter, sister, or granddaughter. The two (25\%) male caretakers of stroke survivors consisted of a son and a husband.

The mean age of the 31 focus group participants was 44.7 years $(\mathrm{SD}=16.8)$ with a range of 21 to 76 years of age. Gender was almost equally divided with $15(48 \%)$ being female and $16(52 \%)$ male. Sixteen $(52 \%)$ of the 31 respondents in the focus groups reported being married. Two participants $(6 \%)$ had a primary education, $21(68 \%)$ had a secondary education and $5(16 \%)$ had a tertiary education. One participant $(3 \%)$ reported no formal education and level of education was unreported for two $(6 \%)$ participants. Twenty-seven $(81 \%)$ participants reported being employed at the time of the focus group.

\subsection{Study design}

In this cross-sectional qualitative study, a thematic analytical approach $^{[25]}$ was used to develop a deeper understanding of perceived barriers to optimal self-management of stroke recovery and prevention. In this approach researchers move their analysis from a broad reading of the data towards discovering patterns and developing themes.

\subsection{Qualitative data collection and analysis}

To further increase credibility and validity of the results, both face-to-face in-depth interviews and focus groups were used to collect narrative data on perceived barriers to stroke recovery and prevention. ${ }^{[24,26]}$ These data collection methods allow interviewees to express their opinions and ideas in their own words, and they are an appropriate strategy for learning the vocabulary and discovering the thinking pattern of the target audience as well as for discovering unanticipated findings and exploring hidden meanings. ${ }^{[27]}$ The participants were interviewed in Luganda, a local language.

The interviews and focus groups explored participant views on barriers relevant to self-management of stroke recovery and prevention, as well as what they felt their community and care providers could do to increase stroke awareness, and improve access to care. A semi-structured interview guide, adapted and translated from the TEAM ${ }^{[20]}$ study, focused the discussion on these main topics and specific topic-related questions. For example, under the topic, "barriers to managing stroke recovery and prevention", the following question was asked: "Can you tell me about things that might get in the way of people staying healthy and preventing another stroke?" Under the topic, "what the community and care providers could do to increase stroke awareness and improve access to care", the following question was asked: "What can be done to increase awareness about stroke prevention and its proper management right from the community to the national level?" The guide also included examples of follow-up probes such as "would you explain further", "please describe what you mean", and "would you give me an example". All interviews and focus groups were audiotaped, transcribed verbatim, and translated into English. All personal identifiers were removed from the final transcripts.

The focus groups and interview transcripts were coded and analyzed separately. Three qualitatively trained investigators independently coded each transcript to ensure consistency and transparency of the coding; discrepancies were resolved by discussion. We used a grounded theory approach to data analysis, encompassing open, axial and sequential coding, and the constant comparative method to generate constructs (themes) and elaborate the relationship among them. ${ }^{[25]} \mathrm{A}$ separate coding dictionary, that included mutually exclusive code definitions, was then constructed for the interviews and focus groups. The coding structure for each was reviewed after a preliminary analysis of a sub-sample of transcripts, and each dictionary was refined through comparison, categorization and discussion of each code's properties and dimensions. ${ }^{[25,28]}$ Integrating insights from a variety of sources and interpretations enabled the researchers to build a deeper picture of perceived barriers to stroke recovery and prevention and facilitate validation through cross verification. ${ }^{[24]}$

\section{RESUlts}

Transcript-based analysis generated 3 major domains of barriers to stroke care and recovery: (1) individual level barriers, (2) family and community level barriers, and (3) health care system and provider level barriers.

\subsection{Individual level barriers}

In Table 1 themes, descriptive codes, and illustrative quotations emerging from the discussion of individual level barriers to stroke care and recovery are presented. We classified these barriers into the 6 categories that reflected the personal 
issues that our respondents faced in managing stroke recov- "Well I often get dreams. I would dream about dead people, I ery and prevention: psychological, behavioral, knowledge, would dream about people that died a long time ago. PR \#3 lifestyle, functional impairment, and self-identity.

\subsubsection{Psychological barriers}

Symptoms of Post-Traumatic Stress disorder (PTSD) were commonly reported by the stroke survivor participants and mainly manifested themselves in the form of sleep and eating disturbances:

"Yes, it happened some time ago and whenever I remembered about it, I couldn't fall asleep and sometimes would even fail to eat food." PR \#1

Other symptoms that were reported included changes in mood and avoidance of other people:

"I am always short tempered to the extent that they start calling me a lunatic. "Grandma has gone mad!" they say. Even my children call me mad! "Mummy has run mad, she quarrels a lot. The sickness got to her brain!” they say.” $P R$ \#9

"Sometimes I might be seated with people but would stand up and go to the house to be alone." PR \#6.

Table 1. Perceived individual level barriers to stroke recovery and prevention $(n=48)$

\begin{tabular}{|c|c|}
\hline Themes and Categories & Illustrative Quotations from Respondents ${ }^{*}$ \\
\hline \multicolumn{2}{|l|}{ Psychological Barriers } \\
\hline PTSD & $\begin{array}{l}\text { "I vividly remember what happened and how I went through the situation and whenever people tried to } \\
\text { remind me about what I went through I would tell them, Let's not talk about that." PR\#5 }\end{array}$ \\
\hline \multicolumn{2}{|l|}{ Behavioral Barriers } \\
\hline $\begin{array}{l}\text { Resistance to seeking } \\
\text { care }\end{array}$ & $\begin{array}{l}\text { "For me the challenge is with us; we don't mind to not know our health status. We go to seek health care } \\
\text { when our conditions are out of hand." FGR\#7 }\end{array}$ \\
\hline $\begin{array}{l}\text { Medication } \\
\text { non-adherence }\end{array}$ & $\begin{array}{l}\text { "Well I swallow them very well though I skip some doses sometimes. If I don't swallow today I would } \\
\text { swallow the next day." PR \#8 }\end{array}$ \\
\hline \multicolumn{2}{|l|}{ Knowledge Barriers } \\
\hline Causes & "If you are stressed for a long time, there is no way you can avoid chances of getting a stroke. PR\#5 \\
\hline Cure \& Prevention & $\begin{array}{l}\text { I think there is no cure for stroke. When the stroke hits you, I think that's all. CTR\#3 } \\
\text { "It cannot be prevented because it just comes suddenly." PR\#9 }\end{array}$ \\
\hline \multicolumn{2}{|l|}{ Lifestyle Barriers } \\
\hline Diet \& sedentary lifestyle & $\begin{array}{l}\text { Because of luxury, we want to fry all that we're to eat. This makes one feel so rich and even the } \\
\text { neighbours regard you as a wealthy person yet you're just killing yourself. FGR \#12 } \\
\text { "You might have a job that requires you to sit from morning to evening and the only time you get up is } \\
\text { when you are going for a short call. So your body then is left weak. "FGR \#16 }\end{array}$ \\
\hline Financial constraints & “Money; money to buy medications and eats, It is scarce.” PR \#2 \\
\hline $\begin{array}{l}\text { Functional Impairment } \\
\text { Barriers }\end{array}$ & $\begin{array}{l}\text { "Now this is the arm which used to write but now I cannot write." PR \#8 } \\
\text { "But I don't walk because of the legs which pain a lot. I don't walk at all!” PR \#3 }\end{array}$ \\
\hline \multicolumn{2}{|l|}{ Self-Identity Barriers } \\
\hline $\begin{array}{l}\text { Changes in role \& } \\
\text { self-esteem }\end{array}$ & $\begin{array}{l}\text { "I am unable to do my work; I can no longer sit and wash a bucket-full of clothes or do home chores } \\
\text { anymore." PR\#5 } \\
\text { "Now her mind tells her that she is useless; she thinks she is not useful to the community anymore." } \\
\text { CTR\#7 }\end{array}$ \\
\hline
\end{tabular}

Note. "Legend: PR = patient respondent; CTR = caretaker respondent; FGR = focus group respondent

\subsubsection{Behavioral barriers}

Medication non-adherence and barriers to seeking mainstream medical care, were the two main behavioral barriers to stroke recovery and prevention cited by the participants:

"So I think also not going for regular medical check-ups was a problem. So even before that, there was a time he was not feeling well and when he went to the doctors they told him, "your blood pressure is not stable; it seems you are over stressed or overworking" but he had dreams he wanted to accomplish. So he took some medicines until he felt okay. In fact I think the problem was that he discontinued that medication." CTR \#5 
In this urban/suburban SSA setting, competing use of traditional healers and herbal traditional treatments sometimes resulted in poor outcomes for stroke care and recovery:

"Some people completely abandon tablets and use herbal medicine so when their blood pressure rises, it really goes high. And even in some cases such people don't adhere well to the herbal medicine prescription." FGR \#24

\subsubsection{Knowledge barriers}

Although participants identified a number of causes of stroke ranging from hypertension, lifestyle factors (improper diet, lack of exercise), lack of preventive care, and witchcraft, stress was cited as the major cause of stroke.

"What I think is that stroke comes from stress. You might be stressed and do nothing about it, or maybe just sleep, consequently you get stroke.” FGR \#12

"I think it is stress. Any problem that has happened can cause one's body to get shocked and it affects the brain as well." CTR \#8

Poverty was overwhelmingly identified as the leading cause of stress:

"Poverty in our homes also predisposes us to stroke; you are always worried about where school fees will come from, what children will eat." FGR \#5

"The poverty is too much. We are now scared for our children; we don't know where we are going to get school fees from. And some of our children died and left grandchildren but we receive no support from their families.” FGR \#29

"Now on that same day it (the stroke) hit me, I was so stressed, I was so poor that I told myself, "Why don't I just die and leave this world?" PR \#3

The majority thinking on cure and prevention among participants was that it could neither be cured nor prevented:

"One thing I know is that the sickness is incurable, so seeing doctors won't make any difference. Now yesterday we were at Kisubi and they asked us to take her back tomorrow but we are not going to do that because there was nothing new they did on her; the medications they prescribed for her is what she has always been swallowing.” CTR \#4

"There is nothing you can do to prevent stroke. In fact when one gets it, that's just God's plan. I would say that people that get stroke are just obese but still I have seen small people with it. I would have said that it comes with age but still there was a nine year kid I saw with a stroke. I would have said that it is because of being physically inactive but all the people I have seen with a stroke were working." CTR \#7

\subsubsection{Lifestyle barriers}

As can be observed from Table 1, high consumption of unhealthy foods and sedentary lifestyle were seen as contributing factors related to stroke recovery and prevention. One focus group participant noted that the change in eating habits from one generation to another might contribute to stroke risk:

"I wonder if we're eating things different from what they used to. Our parents used to feed us with African eggplants and green leafy vegetables but now our children don't know how even a pawpaw looks like! Our children will be prone to diseases because our children don't even know African eggplants.” FGR \#30

While another respondent cited "laziness" as the reason people persisted in not eating wisely:

"Some people are just lazy when it comes to eating African eggplant; they think it is just a joke, yet African eggplant is something which should be served with food daily." FGR \#21

In addition to sedentary life styles and eating unhealthy foods, participants identified lack of money to buy food and medicines as a major barrier to stroke recovery and prevention:

"Sometimes there are financial challenges where you fail to do things that you should have done. For instance you might want to buy something to eat but fail to get the money. In that way you don't have any way of preventing stroke." CTR \#3

"It is capacity! Capacity in form of money to buy the medications is a great challenge to us in that we even end up dying!" FGR \#1

\subsubsection{Functional impairment and self-identity barriers}

Caretakers described patients' post-stroke functional impairments in mobility, fine motor skills and speech, as causes for changes in their mood and loss of self-identity:

"Sometimes he becomes very moody especially when he fails to express himself. You know when you try to express yourself but fail, there is a way you feel. So his moods definitely changed." CTR \#5

"Well sometimes she just breaks down into tears. She would suddenly start lamenting, "Imagine I used to do this and that but I cannot do it anymore." Even when we are going for a party and we tell her to dress up, she would say, "what will people say?" I mean, she is not happy. So the torture she has is thinking about how she used to be a strong woman who could do this and that all by herself which is no more." CTR \#4

In summary, respondents in the study cited many personal 
barriers to stroke recovery and prevention that included PTSD, resistance to seeking care, medication non-adherence, unhealthy lifestyles, functional impairment, and a paucity of knowledge about stroke. However, the main cause of stroke, and the largest barrier to recovery and prevention efforts, was perceived as the stress associated with living in poverty.

\subsection{Family and community level barriers}

Table 2 displays themes, descriptive codes, and illustrative quotations emerging from the discussion of family and community level barriers to stroke care and recovery. Three key barrier categories were: (1) family issues, (2) caretaker burden, and (3) lack of community support.

Table 2. Perceived family and community level barriers to stroke recovery and prevention $(n=48)$

\begin{tabular}{|c|c|}
\hline Themes and Categories & Illustrative Quotations from Respondents ${ }^{*}$ \\
\hline \multicolumn{2}{|l|}{ Family Issues } \\
\hline Lack of support & $\begin{array}{l}\text { "Carrying that water to the bathroom to bathe, I would have to first plead to these kids to } \\
\text { carry the water for me. I have to also plead to them to prepare meals. I would as well tell her, } \\
\text { "come and support me move from here, I cannot do it on my own." PR\#9 }\end{array}$ \\
\hline Gender role issues \& tensions & $\begin{array}{l}\text { "Now I am talking as a lady; so if it was me in his position, matters would even be worse. At } \\
\text { least we women are caring but it is so hard for a man to change his life completely to stay at } \\
\text { home fulltime to take care of the patient. I have only met a few ladies that are being taken care } \\
\text { of by men." CTR \#5 }\end{array}$ \\
\hline \multicolumn{2}{|l|}{ Caretaker Burden } \\
\hline Lack of information & $\begin{array}{l}\text { "There is lack of information about this illness about how to handle it. Personally I had to do } \\
\text { 'trial and error'; nobody talks about stroke the way they do for malaria. CTR \#3 }\end{array}$ \\
\hline Increased responsibilities & $\begin{array}{l}\text { "Now it's like she is a baby again; I have to wash for her every day yet she sometimes urinates } \\
\text { in her clothes." CTR\#6 }\end{array}$ \\
\hline Decreased income & $\begin{array}{l}\text { "You see we sometimes even fail to get money and we would really see that the situation is so } \\
\text { tough. In fact we even fail to get food sometimes!" CTR\#8 }\end{array}$ \\
\hline Changes in role \& lifestyle & $\begin{array}{l}\text { "Now I had to change whatever I was doing since I had to be at home full time by his side. It } \\
\text { was a total dramatic change of my life." CTR \#1 }\end{array}$ \\
\hline PTSD & $\begin{array}{l}\text { "Well I would have dreams about her (patient) when she is dead. So whenever I would put my } \\
\text { head to rest, I would get illusions of her and then I would not sleep again, in the dreams she } \\
\text { would appear in a stroke, in the condition in which she is right now." CTR \#6 }\end{array}$ \\
\hline \multicolumn{2}{|l|}{ Lack of Community Support } \\
\hline Poor sanitation & $\begin{array}{l}\text { "We really failed to get a real place where to pour rubbish. The other thing is that we have } \\
\text { few latrines; you may find only one which is also extremely dirty. So we have that challenge. } \\
\text { FGR \#20 }\end{array}$ \\
\hline Community isolation \& attitudes & $\begin{array}{l}\text { "I heard people say, "Is it stroke? That one is finished." So when you talk like that even in } \\
\text { front of the patient, the patient loses hope." FGR\#14 }\end{array}$ \\
\hline Lack of stroke education programs & $\begin{array}{l}\text { “...we don't have any education seminars to teach people what really causes stroke; how to } \\
\text { behave, how to act when you see a sign, and what to avoid.” CTR \#1 }\end{array}$ \\
\hline
\end{tabular}

Note. ${ }^{*}$ Legend: PR = patient respondent; CTR = caretaker respondent; FGR = focus group respondent

\subsubsection{Family issues}

In some instances, societal changes and the breakdown of traditional family structures were blamed for the lack of family support for stroke survivors:

"The general trend of change in the culture is the main problem. In the past we used to stay with the aunties, the uncles and so on. Now the extended families have broken down and unfortunately no structures have been made to replace the ties that would have been brought by extended families. It is very helpful because when you are in an extended family, there is always a granddaughter to bring you water or fire- wood when you are sick. Secondly, in an extended family, you are confident that even if your husband dies someone else in the family would take care of you. So this social breakdown of structures has caused a lot of problems especially in towns because in towns, to some people this might be their ancestral place. So the urbanization then comes and finds you there which means you have nowhere to go. So coping to that town life would be hard and consequently you would find the elders alone and no one to take care of them." CTR \#5

In addition, gender role issues and tensions within the family 
produced increased stress for the mostly female caretakers:

"This stresses me a lot because he (son) goes for drinking binges and gets back home very late in the night when I am sleeping, and I have to wake up to open up for him. I wasn't aware that he got arrested that day, and I asked God for forgiveness because I didn't lock him out intentionally.” CTR \#8

\subsubsection{Caretaker burden}

Participants were quite vocal about the onerous burden faced in the day-to-day efforts in caring for a stroke survivor. As illustrated in Table 2, the lack of information about stroke care and recovery left most caretakers to employ 'trial and error' methods in the care of the patient. Changes in role, decreased household income, and increased caretaker responsibilities, often resulted in physical and emotional stress:

"First of all she is heavy. You see she is a tall lady, so carrying her is not easy. So I end up with a backache and chest pain." CTR \#6

"Of course I get stressed because right now, I have to do everything that he used to do. I have to even take care of the things at home. If there is a problem anywhere I am the one supposed to do it. When it comes to burying people I am the one who has to go. I am the one to deal with everything and also to make decisions." CTR \#4

Interestingly, the caretakers experienced the same symptoms of PTSD as did the stroke survivors. These included sleep and eating disturbances, nightmares, failure to concentrate, as well as the constant worry about stroke recurrence:

"Yes, I often fear she will have another stroke attack. I am really scared about that. I cannot be settled. I also think, "It might happen to me too." CTR \#1

\subsubsection{Lack of community support}

In addition to concern about public health issues like waste management and poor sanitation, participants felt strongly that there was a lack of attention to educating the community about stroke and that, unlike malaria:

"It is not a disease the government has invested a lot of energy to teach people what stroke is, how it comes and how to prevent it. Formerly, we used to think that it is a disease for whites and the educated people. Now it is going down even to the local people." CTR \#5

Negative attitudes about the effects of stroke, and community isolation posed additional barriers to stroke recovery and prevention:

They think that the patient will not get better anyway. One would say, "Is it stroke? If it is, then we are just wasting our 14 time." So in that case people don't even bother to take care of the person because they know that s/he is about to die." FGR \#24

"You know there is a lot of isolation in towns. For instance each house has a fence and you might not even know who the neighbor is. So you might not even be able to talk to each other yet sometimes you just have to talk to somebody to feel comfortable." FGR \#6

Because of this sense of being forgotten by the community, one participant proposed a "self-help" group approach as an antidote to decreasing the sense of isolation felt by stroke survivors:

"Maybe there should be a club where the patients meet and share their experiences. Because this patient will say that I went through that like this while the other would say I went through it like this. You see it is a hard time if you were a person who always moved in the public but when you got the stroke you became confined in the house and lesser people come to see you. So I think there should be an association so that they can meet to share experiences. So through that, one patient would say, "I tried this product, maybe it will help you if you try it” CTR \#5

In summary, respondents in the study cited many family and community barriers related to stroke recovery and prevention that included societal breakdown of traditional family structures, negative community attitudes about stroke, and overwhelming caretaker burden which was often accompanied by symptoms of PTSD. The lack of community and government support for stroke education programs was perceived as a major barrier to stroke recovery and prevention.

\subsection{Healthcare system and provider level barriers}

Table 3 shows themes, descriptive codes, and illustrative quotations emerging from the discussion of healthcare system and provider level barriers to stroke care and recovery. There were 2 key categories of barriers: (1) access to healthcare system issues, and (2) provider issues.

\subsubsection{Access to healthcare system issues}

As noted in Table 3, access issues related to healthcare facilities was a major problem for the participants. These facilities were most often located far from the patients' homes and required transportation, which most people either did not own, or have money for. This was compounded by long waiting times to see a doctor and sometimes being triaged to another hospital:

"So when we got there, they said, 'We can't handle that one. They (family) then picked me up and took me to another hospital where they just ignored us. In fact it was a public

ISSN 2377-7338 E-ISSN 2377-7346 
holiday and they said, "how do you bring a patient yet we are celebrating a public holiday?" I then thought, 'Won't we fall sick on public holidays?' So we left that place but someone added, "You won't go far before she dies!' my grandson then said, "If she is to die, she can as well die from here, let's take her." PR \#3

Poor maintenance and unhygienic conditions in some hospitals were also described by some participants:

"There are some places you go to and you desire to have died instead. You go to a place and the treatment bed is just so unhygienic, you even find charcoal stoves underneath. You can't see this person opening up a syringe but he comes to inject you when the medicine is already in the syringe. At that point, you just feel sicker!” FGR \#1

As were the scarcity of available medications:

"With health, it is with the drugs in the hospitals. When you get there with a patient who is in critical condition, they tell you the next morning, "We don't have any drugs, so please go to a bigger facility.” FGR \#5

Table 3. Perceived healthcare system and provider level barriers to stroke recovery and prevention $(n=48)$

\begin{tabular}{|c|c|}
\hline Themes and Categories & Illustrative Quotations from Respondents* \\
\hline \multicolumn{2}{|l|}{ Access to Hospitals } \\
\hline Location & $\begin{array}{l}\text { "The health facilities are far away from us. You see time passes and we start pondering about } \\
\text { where to take her. That thing is so disturbing!" CTR\#1 }\end{array}$ \\
\hline Long waiting times & $\begin{array}{l}\text { "Well there are times you can go to the hospital but fail to see the doctor. You don't get } \\
\text { attention or sometimes spend a whole day without getting treatment." PR \#6 }\end{array}$ \\
\hline Financial constraints & $\begin{array}{l}\text { "The greatest challenge is with health facilities; you go there for health care when there's no } \\
\text { medicine, they just ask you to go and buy it from somewhere else yet you have no money." FGR } \\
\text { \#22 }\end{array}$ \\
\hline Poorly maintained facilities & $\begin{array}{l}\text { "There are like } 3 \text { times I have passed that facility when power has gone and the entire place is } \\
\text { dark and I really wonder; if a woman if giving birth, how is she handled?" FGR \#19 }\end{array}$ \\
\hline \multicolumn{2}{|l|}{ Healthcare Provider Issues } \\
\hline Appointment difficulties & $\begin{array}{l}\text { "Getting an appointment is a problem. I felt so bad that day because I was in pain but when I } \\
\text { called him he told me he had reached the maximum number of patients he was supposed to work } \\
\text { on that day." PR \#3 }\end{array}$ \\
\hline Poor attitudes & $\begin{array}{l}\text { "Some doctors are so rude that even when he's telling you something, he speaks in a way that } \\
\text { shows that he doesn't care about your health but only following what he was taught to do." } \\
\text { FGR \#11 }\end{array}$ \\
\hline Inadequate disease investigation & $\begin{array}{l}\text { "When I go there he just writes down medicine. This person never examines me or asks me } \\
\text { anything, he just asks me to go for medicine and I wonder how he does it." FGR \#21 }\end{array}$ \\
\hline Poor communication skills & $\begin{array}{l}\text { "No, they didn't tell me any of that. No, all they say is "go and swallow those tablets. You will } \\
\text { swallow them at this time." PR \#6 }\end{array}$ \\
\hline
\end{tabular}

Note. ${ }^{*}$ Legend: PR = patient respondent; CTR = caretaker respondent; FGR = focus group respondent

\subsubsection{Healthcare provider issues}

Table 3 also displays participants' perceived barriers to receiving stroke care from healthcare providers. In addition to appointment difficulties, poor attitudes towards patients, adequate disease investigation, lack of follow-up, and poor written and verbal communication were reported:

"The (clinical) doctor however never follows up on you when you are discharged until you go back with another problem." CTR \#5

"They never tell me what I am suffering from after diagnosis, they just write down things and prescribe medicine. Even I can't understand their handwriting so I just assume that I may have malaria depending on the medicine they have prescribed." FGR \#10

Published by Sciedu Press
The main provider issue, however, appeared to be insufficient information given about stroke management:

"I needed further explanation about stroke. All they did was to treat the patient and when they realized that there was an improvement, they gave us their bill." CTR \#1

Finally, the participants in this study were very vocal about the need for increasing stroke awareness in the community as part of recovery and prevention efforts. As can be observed from Table 4, they had many ideas about how to disseminate stroke information, from holding community education meetings and seminars, door to door visits by health workers, engaging local leaders to spearhead projects, as well as using print and local media to spread the word about stroke. 
Table 4. Participants' recommendations for increasing stoke awareness in the community $(n=48)$

\begin{tabular}{ll}
\hline Themes and Categories & Illustrative Quotations from Respondents" \\
\hline "Health workers should come around and sensitize people. They should just come and teach \\
because not all people are aware about stroke. There are several places; like local \\
chairmen's places, parents' homes, even at schools. We also have a private health facility in \\
this area, he can allow health workers to come and sensitize the community from his place. \\
People in the community can mobilize others and inform them that health workers are coming \\
for health education.” PR \#1 \\
"Maybe also if you move home to home, In fact I think that is the best approach because in \\
that case, you practically get to one's home to help them. With the communal approach \\
however, not everyone has time for such." CTR \#4 \\
"I think we can sensitize the local leaders, especially the vice chairperson. So we can call \\
them and feed them with this gospel and we should do this at least quarterly. Some of them are \\
good and when they are given information to take to the community, they deliver it!” CTR \#7 \\
"You need to have films or use televisions because they are now so common; you show these \\
things and people see. There’s also a wedding program on Bukedde which people like so \\
much; we can again use that and we put our program on it." \\
FGR 2
\end{tabular}

Note. ${ }^{*}$ Legend: $\mathrm{PR}=$ patient respondent; CTR = caretaker respondent; FGR = focus group respondent

\section{Discussion}

In this well-characterized sample of participants in an urban/suburban Ugandan population, qualitative analysis identified a number of barriers to stroke recovery and prevention that have important implications for policy and practice. Barriers to stroke recovery and prevention spanned individual, family/ community, and provider/ healthcare system domains. This is consistent with McLeroy's ${ }^{[29]}$ social ecological model of health behavior. This model posits that behavior, actions, and events, are influenced by individual, interpersonal, organizational, community and policy factors.

While poverty and access to care were paramount issues related to stroke recovery and prevention among the participants, stress was cited as the most common risk factor for stroke. This finding is consistent with those of two population-based surveys on stroke knowledge in Uganda ${ }^{[12,21]}$ and a qualitative study among young AfricanAmerican men and their caretakers in the United States. ${ }^{[18]}$ Importantly, a recent meta-analysis of 14 studies (10 cohort, 4 case control) involving a total of 10,130 strokes, found that perceived psychosocial stress is independently associated with increased risk of stroke. ${ }^{[30]}$

The DSM-V (Diagnostic and Statistical Manual of Mental Disorders) defines PTSD as a trauma and stressor-related disorder, comprising four core symptomatic clusters: intrusion, avoidance, negative alteration in cognition and mood, and alterations in arousal or reactivity. ${ }^{[0]}$ Both the stroke survivors and caretakers in the present study exhibited many of these same symptomatic clusters of PTSD. These findings of post-stroke PTSD in our sample are consistent with the findings from a meta-analytic review of nine articles (1,138 participants) on prevalence of PTSD in survivors of stroke and transient ischemic attack (TIA) in the USA and Europe. Findings from this meta-analysis suggest that 1 in 4 stroke or TIA survivors develop PTSD up to a year after the event. ${ }^{[31]}$ In addition, Noble and Schenk ${ }^{[32]}$ found that the elevated levels of PTSD found in caretakers of stroke survivors might explain why these persons report concerning levels of psychiatric symptomatology and psychosocial disability. Post-stroke PTSD has not only been shown to impact mental health and quality of life, ${ }^{[33]}$ but has also been associated with an increased risk of medication non-adherence, ${ }^{[34]}$ and may increase the risk for recurrent stroke. ${ }^{[31]}$

Because stress and PTSD are both powerful drivers for recurrent stroke, healthcare providers should consider screening for both during visits. In addition, the dissemination of information on recognizing the symptoms of stress and PTSD, along with suggestions for using stress management techniques, could be incorporated into community outreach programs.

Qualitative findings on the gross deficit in stroke knowledge among our study sample is consistent with findings from previous population survey studies in Uganda. ${ }^{[12,21]}$ However, in this qualitative study, participants were quite vocal about suggested methods of disseminating stroke information to the community (see Table 4), most of which were used in previous successful models for increasing awareness and prevention of HIV and Malaria in Uganda. ${ }^{[35,36]}$ In the words of one study participant: 
"They should do like they do for HIV; they should go to com- Uganda. munities and sensitize people!" CTR \#5

Indeed, Uganda is notable for its early and dramatic declines in HIV burden compared to much of the developing world. The success story of HIV prevention in Uganda has been attributed to behavior change programs largely developed by the Ugandan government and local NGOs including faith based, women's, people living with aids, and other community groups ${ }^{[37]}$ It is likely that successful stroke reduction on a population level will similarly require a multi-pronged approach that includes education, behavioral modeling, access to care, and changes in attitudes towards lifestyle factors that increase stroke risk. Prevention and management of stroke, which has far less stigma than HIV, could be expected to yield even better results on behavior change.

Finally, the issue of how traditional healing approaches and the mainstream medical model of care can co-exist needs to be considered. In Uganda, the ratio of biomedical practitioners to the population is approximately 1:20,000 while the rate of traditional healers can be as low as $1: 200 .^{[38]}$ Our study participants' use of herbal medicines along with western medicines was not unusual, and many supported the integration of both western and traditional practitioners into the healthcare delivery system:

"It (integration) would be helpful in exchanging ideas. For instance in the case of hypertension, the herbalist says that he can treat it effectively and the modern doctor also says that he can finish it. So if they join that knowledge it would benefit us the people." CTR\#7

Recognizing the widespread reliance on traditional medicine, and the central role it plays in many communities, the World Health Organization (WHO), ${ }^{[38]}$ supports the integration of traditional medicine into national health systems in combination with national policy and regulation for products, practices, and providers. Still to be resolved issues include how mainstream medical providers might address the issues of limited patient resources with respect to therapeutic agents. For instance, patients may have to choose between paying for a standard antihypertensive drug from their pharmacy vs. a treatment from their local traditional healers. Another issue to be resolved are circumstances where mainstream practitioners and traditional healers provide competing or very different management recommendations. Such considerations will be important to weigh when developing and planning for stroke prevention and recovery programs in

\section{Limitations}

While our findings on perceived barriers to stroke recovery and prevention in an urban community in greater Kampala have implications for informing policy and care, there are some limitations. Patients with stroke, their caretakers, and those at-risk for stroke, who receive or seek care in other settings in Uganda, may have different experiences with, and different types of encounters with, providers and healthcare systems. The small convenience sample and the conduct of the study in a single urban area in Uganda may limit transferability of the study findings. However, these limitations are offset, to some extent, by the use of rigorous qualitative methods described in the study and our use of the Consolidated Criteria for Reporting Qualitative research (COREQ) ${ }^{[39]}$ to improve the rigor, comprehensiveness and credibility of the interviews and focus groups. These self-report methods are direct, versatile, and yield information that would be difficult, if not impossible, to gather by other means.

\section{Conclusions}

Stroke risk and stroke burden are increasing in Sub Saharan Africa. This qualitative evaluation in a Ugandan urban/suburban sample suggests that stroke risk reduction efforts implemented at the patient, community, and healthcare system levels are needed. These efforts could, perhaps, be modeled along the lines of a previous very successful public health initiative to reduce HIV burden in Uganda.

\section{ACKNOWLEDgements}

This study was supported by a grant from the National Institute of Neurological Disorders and Stroke of the National Institute of Health R21NS094022-01.

\section{Conflicts of InTEREST Disclosure}

Dr. Sajatovic declares the following potential conflict of interest with respect to research grants within the past 3 years: Merck, Alkermes, Janssen, Reuter Foundation, Woodruff Foundation, Reinberger Foundation, National Institute of Health (NIH), Centers for Disease Control and Prevention (CDC) Consultant: Bracket, Otsuka, Pfizer, Sunovion, Neurocrine, Supernus. In addition, the following royalties from: Springer Press, Johns Hopkins University Press, Oxford Press, UpToDate, Lexicomp, and CME activities from the American Physician's Institute, MCM Education, CMEology. All other authors declare no potential conflicts of interest. 


\section{REFERENCES}

[1] Feigin VL, Forouzanfar MH, Krishnamurthi R, et al. Global and regional burden of stroke during 1990-2010: findings from the Global Burden of Disease Study 2010. Lancet. Jan 18 2014; 383(9913): 245254. https : //doi .org/10.1016/S0140-6736(13)61953-4

[2] Chin JH. Stroke in sub-Saharan Africa: an urgent call for prevention. Neurology. Mar 27 2012; 78(13): 1007-1008. PMid: 22454267. https://doi.org/10.1212/WNL . Ob013e318248df 95

[3] Beaglehole R, Bonita R, Alleyne G, et al. UN High-Level Meeting on Non-Communicable Diseases: addressing four questions. Lancet. Jul 30 2011; 378(9789): 449-455. https://doi.org/10.1016/ S0140-6736(11)60879-9

[4] Strong K, Mathers C, Bonita R. Preventing stroke: saving lives around the world. Lancet neurology. Feb 2007; 6(2): 182-187. https://doi.org/10.1016/S1474-4422(07)70031-5

[5] Organization. WH. Global Burden of Disease (GBD) 2004 update. Geneva, Switzerland: WO; 2008.

[6] Connor MD, Walker R, Modi G, et al. Burden of stroke in black populations in sub-Saharan Africa. Lancet neurology. Mar 2007; 6(3): 269278. https : //doi.org/10.1016/S1474-4422(07)70002-9

[7] O’Donnell MJ, Xavier D, Liu L, et al. Risk factors for ischaemic and intracerebral haemorrhagic stroke in 22 countries (the INTERSTROKE study): a case-control study. Lancet. Jul 10 2010; 376(9735): 112-123. https://doi.org/10.1016/S0140-673 $6(10) 60834-3$

[8] Etyang AO, Scott JA. Medical causes of admissions to hospital among adults in Africa: a systematic review. Glob Health Action. 2013; 6: 1-14. https://doi.org/10.3402/gha.v6i0.19090

[9] Furie KL, Kasner SE, Adams RJ, et al. Guidelines for the prevention of stroke in patients with stroke or transient ischemic attack: a guideline for healthcare professionals from the american heart association/american stroke association. Stroke; a journal of cerebral circulation. Jan 2011; 42(1): 227-276. PMid: 20966421. https://doi.org/10.1161/STR.0b013e3181f7d043

[10] Cossi MJ, Preux PM, Chabriat H, et al. Knowledge of stroke among an urban population in Cotonou (Benin). Neuroepidemiology. 38(3): 172-178. PMid: 22472485. https ://doi .org/10.1159/000336 862

[11] Wahab KW, Okokhere PO, Ugheoke AJ, et al. Awareness of warning signs among suburban Nigerians at high risk for stroke is poor: a cross-sectional study. BMC Neurol. 2008; 8: 18. PMid: 18513399. https://doi.org/10.1186/1471-2377-8-18

[12] Nakibuuka J, Sajatovic M, Katabira E, et al. Knowledge and Perception of Stroke: A Population-Based Survey in Uganda. ISRN Stroke. 2014. PMid: 25202472. https ://doi .org/10.1155/2014/309 106

[13] Lorig K. Chronic disease self-management programs: insights from the eye of the storm. Front Public Health. 2015; 253 (4) :1-3 https://doi.org/10.3389/fpubh.2014.00253

[14] Battersby M, Hoffmann S, Cadilhac D, et al. 'Getting your life back on track after stroke': a Phase II multi-centered, single-blind, randomized, controlled trial of the Stroke Self-Management Program vs. the Stanford Chronic Condition Self-Management Program or standard care in stroke survivors. International journal of stroke: official journal of the International Stroke Society. Apr 2009; 4(2): 137-144.

[15] Fu D, Fu H, McGowan P, et al. Implementation and quantitative evaluation of chronic disease self-management programme in Shanghai, China: randomized controlled trial. Bulletin of the World Health Organization. 2003; 81(3): 174-182. PMid: 12764513.

[16] Amos A. Stroke Self Management Program Evaluation Report. Melbourne, Australia: National Stroke Foundation; 2006.
[17] Cadilhac D. Evaluation Report: National Stroke Foundation Self Management Program-Final Results of Pilot Program. Melbourne, Australia: National Stroke Research Institute; 2006.

[18] Blixen C, Perzynski A, Cage J, et al. Stroke recovery barriers among young African American men: Potential avenues to reduce health disparities. Topics in Stroke Rehabilitation. 2014; 21(5): 432-442. PMid: 25341388. https://doi.org/10.1310/tsr2105-432

[19] Blixen C, Perzynski A, Cage J, et al. Using focus groups to inform the development of stroke recovery and prevention programs for younger African-American (AA) men. Topics in Stroke Rehabilitation. 2015; 22(3): 221-230. PMid: 26084323. https://doi.org/10.1179/ $1074935714 \mathrm{Z} .0000000006$

[20] Sajatovic M, Tatsuoka C, Welter E, et al. A Targeted Selfmanagement Approach for Reducing Stroke Risk Factors in AfricanAmerican Men who have had a Stroke or Transient Ischemic Attack. American Journal of Health Promotion (In Press). https : //doi.org/10.1177/0890117117695218

[21] Kaddmukasa M, Kayima J, Nakibuuka J, et al. A cross-sectional population survey on stroke knowledge and attitudes in Greater Kampala, Uganda. Cogent Medicine. 2017. https: /doi .org/10.1080/233 $1205 x$. 2017. 1327129

[22] Creswell JW. Qualitative Inquiry \& Research Design: Choosing Among Five Approaches. Thousand Oaks, CA.: Sage; 2007.

[23] Denzin NK, Lincoln YS. The discipline and practice of qualitative research, in N.K. Denzin \& Y.S. Lincoln (Eds.), The Sage Handbook of Qualitative Research (3rd ed.). Thousand Oaks, CA: Sage; 2005 1-32 p.

[24] Cresswell JW, Miller DL. Determining validity in qualitative inquiry. Theor Pract. 2000; 39 (3): 4-7. https ://doi .org/10.1207/s154 30421tip3903_2

[25] Strauss A. Qualitative Analysis for Social Scientists. New York, NY: Cambridge University Press; 1988.

[26] Patton MQ. Enhancing the quality and credibility of qualitative analysis. Health Services Research. 1999; 34(5): 1189-1208. PMid: 10591279.

[27] Marshall C, Rossman G. Designing Qualitative Research. 4th.ed. Thousand Oaks, CA: Sage; 2006.

[28] Bradley EH, Curry LA, Devers KJ. Qualitative data analysis for health services research: developing taxonomy, themes, and theory. Health Services Research. 2007; 42(4): 1758-1772. PMid: 17286625 https://doi.org/10.1111/j.1475-6773.2006.00684.x

[29] McLeroy K, Bibeau D, Steckler A, et al. An ecological perspective on health promotion programs. Health Educ Q. 1988; 15(4): 351-377. PMid: 3068205. https ://doi.org/10.1177/10901981880150 0401

[30] Booth J, Connelly L, Lawrence M, et al. Evidence of perceived psychosocial stress as a risk-factor for stroke in adults: a meta-analysis. BMC Neurology. 2015; 15: 233. https://doi.org/10.1186/s1 2883-015-0456-4

[31] Edmondson D, Richardson S, Fausett JK, et al. Prevalence of PTSD in survivors of stroke and transient ischemic: A meta-analytic review. PloS ONE. 2013; 8(6): e664435. https://doi.org/10.1371/jo urnal pone. 0066435

[32] Noble AJ, Schenk T. Posttraumatic stress disorder in the family and friends of patients who have suffered spontaneous subarachnoid hemorrhage. Journal of Neurosurgery. 2008; 169(6): 1027 1033. PMid: 19035715. https://doi.org/10.3171/JNS. 2008 .109 .12 .1027

[33] Ferro JM, Caeiro L, Figuera ML. Neuropsychiatric sequelae of stroke. Nat Rev Neurol. 2016; 12: 269-280. PMid: 27063107. https://doi.org/10.1038/nrneurol.2016.46 
[34] Kronish IM, Edmondson D, Goldfinger JZ, et al. Posttraumatic stress disorder and adherence to medication in survivors of stroke and transient ischemic attacks. Stroke. 2012; 43: 2192-2197. PMid: 22618380. https://doi.org/10.1161/STROKEAHA.112.6552 09

[35] Slutkin G, Okware S, Naamara W. et al. How Uganda reversed its HIV epidemic. AIDS Behav. 2006; 10: 351-361. https://doi.or g/10.1007/s10461-006-9118-2

[36] Mbonye A, Neema S, Magnussen P. Preventing malaria in pregnancy: a study of perceptions and policy implications in Mukono district, Uganda. Health Policy and Planning. 2006; 21(1): 17-26. PMid: 16317032. https://doi.org/10.1093/heapol/czj002

[37] Green EC, Halperin DT, Nantulya V, et al. Uganda's HIV pre- vention success: The role of sexual behavior change and the $\mathrm{Na}$ tional response. AIDS and Behavior. 2006; 10(4): 335-346. https : //doi.org/10.1007/s10461-006-9073-y

[38] World Health Organization (WHO). WHO Traditional Medicine Strategy 2014-2023. Accessed February 23, 2017.

[39] Tong A, Sainsbury P, Craig J. Consolidated criteria for reporting qualitative research (COREQ):a 32-item checklist for interviews and focus groups. International Journal for Quarterly Health. 2007; 19(6): 349-357. PMid: 17872937. https://doi.org/10.1093/intqhc /mzm042

[40] American Psychiatric Association. Diagnostic and Statistical Manual of Mental Disorders. 2013; 5th ed. Arlington, VA: American Psychiatric Publishing. 